\title{
Effects of Quality Considerations and Climate/Weather Information on the Management and Profitability of Cotton Production in the Texas High Plains
}

\author{
Megan L. Britt, Octavio A. Ramirez, and Carlos E. Carpio
}

\begin{abstract}
Production function models for cotton lint yields, seed yields, turnout, and lint quality characteristics are developed for the Texas High Plains. They art used to evaluate the impacts of quality considerations and of climate/weather information on the management decisions and on the prolitability and risk of irrigated cotton production systems. It is concluded that both quality considerations and improved climatic/weather information could have substantial effects on expected profitability and risk. These elfects mainly occur because of changes in optimal variely selection and irrigation water use fevels. Quality considerations in particular result in significantly lower irrigation water use levels regardless of the climate/weather information assumption. which has important scarce-resource use implicaltions for the Texas High Platins.
\end{abstract}

Key. Wrords: climatic/weather infornation, cotton cuality, ground water resource use, risk and uncertainty, Texas High Plains

JEL. Classifications: D21, D24. D61, D81, D84

The Texas High Plains is one of the most important cotton producing areas of the United States, accounting for nearly $20 \%$ of the total U.S. production during the last decude. Yields in this areal are determined by a lew critical facrors, including climatic conditions, irrigation water rates, fertilization methods and

Megan L. Britt is agricultural economist. Pioneer HiBrecl, Johnston, IA. Octavicı A. Ramirex is atsscreiate prolessor. Departmem of Agricultural and Applied Economics, Texits Tech University. Luhbock, TX. Carlos E. Carpio is gradtate research atsistant, Department of Economies, North Carolina State University. Ralleigh. NC. The authors acknowledge the linancial support of USDA/CSREES through the International Cotton Research Center (ICRC) of Texas Tech University, and of Cotton Incorporaled, which partitlly funcled this research, the helplul conments and suggestions of Drs. Don Eihridge, Plitlip Johnsson. and Eduardo Segirra. rates, and variety selection. These factors have to be collectively considered and managed to increase profitability and reduce protit variation. Because of the existence of significant premiums and discounts for lint quality, producers would benefit from a better, more quantitutive understanding of the determinunts of cotton quality and of the agronomic and economic tradeofts between yield and quality.

A common management strategy for increasing profits has been to improve lint yields by adopting more input-intensive varieties or technologies. which often results in higher costs of production (Bradow and Davidonis). This is becoming less feasible for producers on the High Plains becaluse of chronically low cotton prices and a reduced availability of irrigation water. A second strategy to increase profits is to identify more economically effi- 
cient input-use rates by considering the relationships between yields and a few critical factors of production. A number of studies focusing on this strategy have been conducted for cotton (Green, Krieg, and Reiter: Morrow and Krieg).

Several studics addressing quality issues in agricultural crop production and marketing have been found in the recent literature. Chiou, Chen, and Capps investigated the impacts of biotechnology on cotton quality and profitability. Beach and Carlson conducted an analysis of herbicide use to determine the value of user safety and water quality. Parker and Zilberman evaluated the quality factors affecting the farm-retail margins of perishable products. Ethridge and Hudson found that cotton producers with limiled information about the prevailing quality premiums/discounts were more likely to make incorrect marketing decisions. Hudson, Ethridge, and Segarra explored the impact of incorrect information about the prevailing quality premiums/discounts on production and marketing processes. Faux and Perry estimated the value of irrigation water, considering its effects on cotton quality and price.

Studies about the impact of climatic or weather variation on production system profitability and risk are less common in the recent literature. Hansen investigited corn farmers' responses to changes in climate and their effects on yields. Kaufmann and Snell built a biophysical model of corn yield, integrating climatic and social determinants. Mjelde et al. used a dynamic programming model to determine the value of seasonal climate forccasts for east-central Illinois corn production.

Although cotton is a major agricultural commodity in the United States, there is no published research that has evaluated the potential for increasing profits and reducing risk by considering the effects of key production management decisions and of climatic variables on both yiclds and the quality of cotton produced. Also, despite the extreme weather variations observed in major cotton-producing regions like the Texas High Plains, the potential effect of the availability and use of improved climatic and weather information on cotton production system management, profitability, and risk has not been evaluated.

This study addresses the issues discussed above by estimating six equations that simultaneously describe the relationships between critical management decisions (variety, irrigation water/nitrogen, and phosphorous fertilizer application rates) and cotton output (lint and seed yield, micronaire, strength, staple, and turnout) in the Texas High Plains under three heat-unit and rainfall patterns. The models are used to evaluate the changes in expected profits and profit variability caused by decreased climatic and weather uncertainty and by considering the effect of management decisions on both the quantity and the quality of the cotton produced.

\section{A Simplified Theoretical Model}

The following is a simple theoretical model of the input use and lint yield decision considcring a single quality attribute:

$$
\begin{aligned}
\gamma & =F\left(R, H U, X_{1}, X_{2}\right), \\
P R & =P R(Q), \quad Q=Q\left(R, H U, X_{1}, X_{1}\right) . \\
H & =\left(P+P R \mid Y-R_{1} X_{1}-R_{2} X_{2}-F C .\right.
\end{aligned}
$$

where $Y$ is lint yields, which depends on ruinfall $(R)$, heat units $(H U)$, and two variable inputs, $X_{1}$ (irrigation water) and $X_{2}$ (fertilizer use); $Q$ is the quality of the lint, which also depends on $R, H U, X_{1}$. and $X_{1}: P R$ is the quality premium or discount per unit of $Y$, which depends on the actual quality: $I I$ is profits. $P$ is the price per unit of $Y_{\text {, and }} R_{1}, R_{2}$, and $F C$ are the costs per unit of variable input $\left(X_{1}\right.$ and $X_{2}$ ) and the fixed costs. The first-order conditions (FOC) for prolit maximization are

$$
\text { (3) } \begin{aligned}
i \Pi / N X_{1}= & P \times F_{1}+P R_{0} \times Q_{1} \times Y \\
& +P R \times F_{1}-R_{1}=0, \text { or } \\
M V P_{1}= & F_{1}|P+P R|+P R_{0} \times Q_{1} \times Y=R_{1} \\
a I 1 / i X_{2}= & P \times F_{2}+P R_{1} \times Q_{2} \times \gamma \\
& +P R \times F_{2}-R_{2}=0, \text { or } \\
M V P_{2}= & F_{2}|P+P R|+P R_{0} \times Q_{2} \times Q \\
= & R_{2+}
\end{aligned}
$$


where $M V P$, and $M V P$, stand for the marginal value of the product of $X_{1}$ and $X_{2}, F_{1}$ and $F_{2}$ are the partial derivatives of $Y=F\left(R, H U, X_{1}\right.$, $X_{2}$ ) wilh respect to $X_{1}$ and $X_{2} ; P R_{Q}$ is the derivative of $P R(Q)$ with respect to $Q$; and $Q$, and $Q_{2}$ are the partial derivatives of $Q=Q(R$, $H U, X_{1}, X_{2}$ ) with respect to $X_{1}$ and $X_{2}$. If the decision maker erroneously assumes that input use does not affect quality (i.e., that $Q_{1}=Q_{2}$ $=0$ ), the effective price is still $P+P R$ (i.e., there will still be a premium or discount for the quality of the cotton produced), and the FOC for profit maximization become

$$
\begin{aligned}
& M V P_{1}=F_{1}(P+P R)=R_{1} . \quad \text { and } \\
& M V P_{2}=F_{2}(P+P R)=R_{2} .
\end{aligned}
$$

Because the actual profits would still be given by Equation (2), it is obvious that an input use decision based on Equation (3) would always result in equal or higher profits than the erroneous input use decision based on Equation (4). If higher isput use increases the value of the quality attribute (i.e., $Q_{1}>0$ and $Q_{2}>0$ ) and this results in a higher premium (i.e., $P R_{Q}>0$ ), then $P R_{Q} \times Q_{1} \times Y>0$ and $P R_{Q} \times Q_{2} \times Y>0$, and quality considerations would always shift the $M V P_{1}$ and $M V P_{2}$ upward and increase the use of both variable inputs. The reverse occurs if higher input use decreases quality.

In the case of cotton, however, multiple quality attributes have to be considered and, depending on the quality attribute and its actual value, the quality "premium" $(P R)$ can be positive or negative-i.e., a premium or at discount. In addition, the quality "premium" can be an increasing or a decreasing function of the value of the quality attribute: $P R_{Q}$ tan be positive or negative (Nelson et al.). Also, it will be established below that the value of the quality attribute maly increase or decrease with higher inpul use (i.e., $Q_{1}$ and $Q_{2}$ can be positive or negative). As a result, the impact of quality considerations on the behavior of a protit-maximizing producer becomes an empirical question.

The effect of the reliability of the weather information available for decision-making can be introduced in the theoretical model above by letting

$$
\begin{aligned}
R^{*} & =A R+\delta_{R}(R-A R), \quad \text { and } \\
H U^{*} & =A H U+\delta_{H U}(H U-A H U),
\end{aligned}
$$

where $R^{*}$ and $H U^{*}$ are the rainfall and heatunit atmounts implicitly assumed for decision making, $R$ and $H U$ are the actual raintall and heat units, $A R$ and $A H U$ arc the long-term average rainfall and heat-unit amounts observed in the area, and $\delta_{k}$ and $\delta_{\mu v}$ can be interpreted as climate/weather information availability toefficients taking values of zero or nne. Specifically, if $\delta_{t}=0$ and $\delta_{m t}=0$, then $R^{*}=A R$ and $H U^{*}=A H U$, which implies that management decisions are made on the basis of average rainfall and heat-unit accumulation. Alternatively, if $\delta_{k}=1$ and $\delta_{m u}=1$, then $R^{*}$ $=R$ and $H U^{*}=H U$, which implies that management decisions are made on the basis of actual rainfall and heat-unit accumulation. The latter is only possible given the availability and use of perfect climate/weather information. The applicability of these two alternative assumptions in the case of irrigated cotton production in the Texas High Plains is discussed below.

The FOC for profit maximization under Equation (5) are as stated in Equation (3), except that $R^{* 5}$ and $H U^{*}$ replace $R$ and $H U$ in the lint yield and quality equations provided in Fipuation (1). Even if $R^{*}$ and $H U^{*}$ enter these equations as intercept shifters only, they will affect the $\mathrm{FOC}$ through $Q P, Q P^{\prime}$, and $Y$. In general, they would be expected to be slope (i.e., marginal physical product) shifters as well and also affect the FOC through $F_{1}, F_{2}$, $Q_{1}$, and $Q_{2}$. Because the actual protits are given by Equation (2) evaluated at $R$ and $H U$, an input use decision based on perfect climate/ weather information (i.e., $\delta_{k}=\delta_{H t}=1$ ) would always result in higher profits than when farming for average weather (i.e., $\delta_{k}=\delta_{t t l}=0$ ). However, as in the case of quality considerations, the uncertainties about the signs of $P R_{Q}, Q_{1}$ and $Q_{2}, Q_{n}$ and $Q_{n u}$ makes it impossible to ascertain the qualitative impact of improved climate/weather information on variable input use and on the quantity and quality 
characteristics of the cotton produced in this particular case. The signs and magnitudes of these responses have to be empirically determined.

\section{Methods and Procedures}

\section{Data Description}

The data set for this research was collected from three field experiments conducted in Lubbock County, Texiss. in 1997, 1998. and 1999. These experiments were planted on May 19 and 13 and June 15 and defoliated on October 13, 15. and 28, respectively. The pooled data set consists of 711 lint yield, seed yield, turnout, micronaire, staple length, and fiber strength value observations, corresponding to I1 varieties under diffetent irrigation water/ nitrogen and phosphorous lertilizer application rates and weather conditions--i.e., the rainfall and heat units accumulated during the cotton growing season. Phosphorts was applied through fertilization at rates ranging from 0 to $73 \mathrm{lbs}$ per acre. Irrigation water, applied through a low energy precision application (LEPA) system, ranged from 3 to 14 acreinches. Nitrogen was also applied through the water at a fixed rate of $6 \mathrm{lbs} / \mathrm{itcre}$ per acre-inch of irrigation water. als recommended by Morrow and Krieg. All water/nitrogen and phosphorus application combinations were repeated for the II cottonseed varieties: Paymaster HS 26. Paymaster HS 200. Delta Pine 2156, Paymaster Tejas, HOL 101. HOL 338. All-Tex Atlas, AFD Explorer. AFD Rocket. All-Tex Toppick, and All-Tex Xpress.

Growing period rainfall and heat-unit mealsurements were collected at the reseirch site. The site received less than average rainfall $(8.5 \mathrm{in}$.) and close to average heat-unit accumutation $\left(1.161^{\circ} \mathrm{C}\right)$ in 1997 . In 1998. a dry year, the plots received little rainfall (5.4 in.) and a relatively high heat-unit accumulation $\left(1,544^{\circ} \mathrm{C}\right)$. During 1999 , the experiment received below avernge heat-unit accumulation $\left(1,022^{\circ} \mathrm{C}\right)$ and rainfall $(6.3 \mathrm{in.})$. These three heat-unit-rainfall combinations were used to estimate the production response functions. The fact that only below-average rainfall ot- curred during the three years when the experimental data were obtained is a potentially important limitation of this study. Specifically. because the marginal physical product of water $\left(M P P_{w}\right)$ is likely higher at low levels of raintall, the concern is that this could result in an overestimation of the $M P P_{w}$ at above-average rainfall, which would affect the economic analysis. This concern is addressed in the results section.

Historical (May-September) heat-unit and rainfall observations at Lubbock County from 1914 to 1999 were used to determine expected prolit levels and profit viriation due to weather (NOAA 2001; National Weather Service). Heat-unit accumulations were calculated from daily temperature data during the normal cotton-growing period in the Texas High Plains. which extends from May to September. Cotton yields were measured at each experimental plot by hand harvesting all cotton bolls within a sample area of 1/1,000 of an acre. The harvested bolls were ginned at a plot gin. A sample of the ginned cotton from each plot was sent to the International Textile Center of Texas Tech University to determine the values of its lint quality attributes. Staple length, strength, and micronaire were measured using high volume instrument tests.

\section{The Yield and Quality Response Functions}

Six yield and quality response functions were estimated using the seemingly unrelated regression procedure, to take advantage of the correlation among the dependent variables lint yield, seed yield, strength, staple, micronaire. and turnout. Each function was initially specified with an intercept and 43 independent variables, including the intercept and slope shifters and interaction terms

$$
\text { (6) } \begin{aligned}
\gamma= & \beta_{01}+\beta_{1} H U+\beta_{2} R F+\sum_{i=2}^{11} \beta_{i-1} V i \\
& +\beta_{13} W A T+\beta_{14} W A T^{2}+\beta_{13} W A T^{3} \\
& +\beta_{16} T P H+\beta_{13} T P H^{2}+\beta_{14} T P H^{\prime} \\
& +\beta_{13} T P H W A T+\beta_{21} H U W A T \\
& +\beta_{21} R F W A T+\beta_{23} H U T P H
\end{aligned}
$$




$$
\begin{aligned}
& +\beta_{33} R F I P H+\sum_{i=2}^{11} \beta_{i+32} V i T P H \\
& +\sum_{i=1}^{11} \beta_{1-32} V i W A T+\varepsilon .
\end{aligned}
$$

where $Y$ is output (lint yield, seed yield, micronaire, strength, staple, or turnout); $H U$ is heat units in degrees Celsius; $R F$ is rainfall in inches; WAT is irrigation water use in acreinches; TPH is total phosphorus applied in lbs per acre; V2-VII are dummy variables for varieties Paymaster HS200, Delta Pine 2156, Paymaster Tejas, HOL 101. HOL 338, All-Tex Atlas, ADF Explorer, ADF Rocket, All-Tex Toppick, and All-Tex Xpress; and $\varepsilon$ is the error term. The omitted variety (VI) is Paymaster HS26.

All of the six initial model specifications included third-degree polynomials with respect to irrigation water/nitrogen and phosphorous fertilizer use. Typical three-stage neoclassical production function surfaces are expected in the case of lint and sced yields, although the third stage of negative marginal returns might not have been reached in the experimental data at hand.

The functional relationships among the three lint quality attributes and variable input use have not been studied in detail, and there is no agreement between cotton production and physiology experts about the general direction or even the existence and practical significance of these relationships (Krieg). Thirddegree polynomials are appealing to model these relations becaluse of their fiexibility to accommodate a variety of functional shapes. The typical drawback of polynomial specifications, exacerbating multicollinearity, is less of a concern in this case because of the randomized experimental design used to generate the data, and parsinony is not a priority, given the relatively large number of observations and degrees of freedom available.

The estimation of nonlinear responses with respect to rainfall and heat units was not feasible because the data were collected under three different rainfall-heat-unit regimes only. The models accounted for differences across varictics through dummy variables used to shift the intercept and the linear trend parameters of the polynomials modeling the responses to water/nitrogen and phosphorus application rates. The models also contained interaction terms that allowed for different yield and quality responses to irrigation waterl nitrogen (phosphorus) depending on the phosphorus (water/nitrogen) application level and the prevailing weather.

The statistical significance of each parameter in the initial models was evaluated by use of two-railed I tests on the basis of heteroskedastic-consistent standard error estimates. The final models presented in the appendix were estimated, excluding all variables whose associated parameters were not statistically different from zero at an $\alpha<.20$. F tests were conducted to verify that the set of parameter restrictions impused in ench of the final models were statistically valid.

\section{The Enpirical Hedonic Profit Equation}

The empirical hedonic profit equation was specified by expanding the theoretical model discussed above to account for multiple quality attributes and the peculiarities of the problem at hand, specifically:

$$
\begin{aligned}
& \text { II = total revenue }- \text { total cost } \\
& =T R(M D, W)-T C(M D, W), \\
& \operatorname{TR}(M D, W) \\
& =\int\left[P_{n}+P O D_{M}[M V(M D, W)]\right. \\
& +P O D_{s}[S V(M D, W] \\
& +P O D_{1,}[L V(M D, W)\} \\
& \times L Y(M D, W) \mid+P_{S} S Y(M D, W) \text {. }
\end{aligned}
$$

$$
\begin{aligned}
& T C(M D . W) \\
&= U C W \times W A T \\
&+9.53\{\mathrm{~V} 1+\mathrm{v} 2+\mathrm{v} 3+\mathrm{v} 4\} \\
&+7.50\{\mathrm{~V} 5+\mathrm{v} 6\} \\
&+7.95\{\mathrm{~V} 7+\mathrm{v} 10+\mathrm{v} 11\} \\
&+8.85\{\mathrm{~V} 8+\mathrm{v} 9\}+0.0875 T P H \\
&+0.0225\{L Y(M D . W) / T U R(M D, W)\} \\
&+ \text { OVC \& FC. }
\end{aligned}
$$


$T R(M D, W)$ calculates the total (gross) revenues per acre. $L Y(M D, W) . S Y(M D, W)$. $M V(M D, W), S V(M D, W)$, and $L V(M D, W)$ are the lint yield, seed yield, micronaire, liber strength, and staple length values predicted by the models. As explained above, each of these is a function of the management decision (MD) and prevailing weather (W). The management decision includes the variety (VI to VI1), irrigation water/nitrogen application rate (WAT) and amount of phosphorous fertilizer $(T P H)$ utilized. Weather includes May-September rainfall and heat-unit accumulation. $\left.P O D_{M}|M V(M D, W)|, P O D_{s} \mid S V(M D, W)\right]$ and $P O D_{L}[L V(M D, W)]$ are the per-pound premiums or discounts received for the micronaire, strength, and staple length values of the cotton lint sold. These depend on the micronaire, strength, and staple values of the cotton produced $(M V, S V$, and $L V)$, which are functions of the $M D$ and $W . P_{n}$ is a "base" price that applies to cotton lint with "baseline" quality values.

The annual averages of the base price and of the quality premium or discount estimates from the Texas Tech University Daily Price Estimation System (DPES) for the 1997/1998, 1998/1999, and 1999/2000 marketing yeurs were used in the analyses for comparative purposes. The DPES is a set of nomlinear models of the relationships between the cotton price preniums/discounts and the quality of the cotton fiber. Therefore, the premium and discount estimates are nonlinear functions of the lint quality values. Three alternative years were used, because the base price and the premium/ discount for any given quality value changes from ycar to year depending on the market conditions. A fixed price per pound of seed $\left(P_{s}\right)$ was used in the profit equation, which was calculated by taking the average of the seed prices reported by the National Agricultural Statistics Service from 1995 to 2000, adjusted for inflation using the 2000 producer price index.

$T C(M D, W)$ calculates the total cost of production per acre, which is also a function of the $M D$ and of the $W$, because weather affects ginning costs through lint yields and turnout. In $T C(M D, W)$, UCW is the cost per acre-inch of irrigation water applied (High Plains Water Conservation District), WAT is irrigution water use in acre-inches, TPH is total amount of phosphorus applied in pounds per acre, TUR $M D, W)$ is the turnout or percentage of marketable lint, which is also a function of the management decision and weather, VI-VII are dummy variables for varieties $1-11$, and $O V C \& F C=\$ 410$ represents other variable costs and tixed costs of irrigated cotton production in the Texas High Plains (Texas Agricultural Extension Service).

On the basis of dealer quotes, the planting costs for the Paymaster, All-Tex, and AFD certitied varieties were estintated at $\$ 9.53 /$ acre, $\$ 7.95 /$ acre, and $\$ 8.85 /$ acre and the cost of planting either HOL 101 or HOL 3.38 at $\$ 7.50$ / acre. The unit cost of purchasing phosphorous fertilizer was assessed at $\$ 0.08 / \mathrm{lb}$. The cost of applying it through fertigation $(\$ 0.0075 / \mathrm{lb})$ was allocated as the rental cost for a 1,000gallon tank and an injection pump, the additional equipment typically needed to use fertigation. Therefore, the cost of fertigation in the profit equation is $0.0875 T P H$. Ginning costs were assumed at $\$ 2.25 / \mathrm{cwt}$ (TASS 1998). The module weight was determined by dividing predicted lint yields by turnout. Thus, in the total cost equation, $0.0225(L Y(M D, W) /$ $T U R(M D, W)\}$ calculates the ginning cost per acre.

\section{Scenarios for the Economic Analyses}

The decision-making behavior of the Texas High Plains irrigated cotton farmers under current and improved degrees of ctimate and weather information availability could only be ascertained through extensive field research beyond the means of the present study. However, the two extreme hypothetical scenarios introduced in the theoretical model above cun be used to evaluate the potential magnitude of the effect of using more reliable climate and weather information on the management, profitability, and risk of irrigated cotton production in the Texas High Plains.

With this in mind, four scenarios were constructed to evaluate whether the consideration of quality, in addition to quantity, when mak- 
ing crop management decisions and whether the availability and use of more reliable climate and weather information could substantially increase protitability and/or reduce risk. All of the scenarios assume precise yield, quality, and turnout predictions from the estimated models and accurate base price and premium/discount schedule estimates from the DPES models and that these are available for decision making.

The first scenario. called quality considerations/perfect weather and climate informition, assumes that the producer makes profit-maximizing decisions considering the impact of the management on both the quantity and the quality of the cotton produced. It also assumes perfect information about the weather and climate that will prevail during the growing season, as defined in the theoretical model above when $\delta_{k}=1$ and $\delta_{m \prime \prime}=$ 1. For this first scenario, the water/nitrogen and phosphorus application levels that maximize the full protit Equation (7) are determined under each of the 86 historical heatunit and rainfall observations available for Lubbock, Texas, for every one of the 11 varieties in the analysis. The corresponding profits are calculated, also using Equation (7) under the assumption that each of these 86 heat-unit-rainfall combinations occurred-i.e., that perfect forecasts were available for making the management decisions. The result is 86 profit levels for cuch variety that reflect the empirical probability distribution of the maximum profits across the likely climate spectrum.

The second scenario, termed no quality considerations/perfect weather and climate information. assumes that the producer makes "myopic" profit-maximizing decisions by considering the impact of the management on the quantity, but not on the quality, of the cotton produced. The water/nitrogen and phosphorus application levels that maximize a "myopic" profit equation, obtained by excluding the term $\left\{P O D_{M}[M V(M D, W)]+P O D_{S}[S V(M D, W)]+\right.$ $\left.P O D_{L}[L V(M D, W)] \times L Y(M D, W)\right]$ from Equation (7), are determined under each of the 86 historical heat-unit and rainfall observations for all 11 varieties. The corresponding profits, how- ever, are calculated using all of Equation (7), with the micronaire, strength, and staple values predicted by the models under the previously determined sets of "myopic" decisions.

The third and fourth scenarios, called quality considerations/average weather and climate and no quality considerations/average weather and climate information. involve the same clements of the first (quality considerations) and second (no quality considerations) scenarios above. With regard to weather and climate, however, they assume that the management decisions are based on the average rainfall and heat-unit accumulations observed during the 1914-1999 cotton growing seasons-i.e., $\delta_{R}=$ $\delta_{H U}=0$ in the theoretical model discussed above.

With regard to weather forecasting, the NEXRAD system is now operational throughout the United States, which has provided for improvements in short-term weather forecasting. Improvements are expected in the near future that will greatly enhance the capabilities of this system (Serafin and Wilson). The Lubbock Forecast Office of the National Weather Service issues forecasts up to 7 days for a 24 county area that includes the extreme southern Texas Panhandle, the South Plains, and parts of the Low Rolling Plains of West Texas. The Climate Prediction Center of the National Oceanic and Atmospheric Administration produces monthly and seasonal forecasts that are available through the Internet (Phillips). Nevertheless, there is no research about the decision-making behavior of the Texas High Plains irrigated cotton farmers under the current state of climate and weather information availability or about whether and how they consider the effects of management decisions on the quality of the colton produced.

However, it could be argued that, on the basis of producer experience alone, it is easier to develop sound management decisions for average climate/weather and price environment conditions. Making decisions that fully account for quality effects and for the potential of nonaverage climate/weather conditions requires reliable quantitative knowledge of how the management (i.e., variety, water, and fertilizer use) and climate/weather variables (i.c., 
rainfall and heat units) interact to affect the six major yield and quality components (lint. seed, micronaire, slaple, strength. and turnout). It also requires precise forecasts of the price premium/discount environment and of the rainfall and heat-unit regime that will prevail during the season. Producers" awareness of the existence of these relations might not be sufficient.

For example, producers likely have some reliable knowledge about the yields and quality of the cotton to be expected from the main varieties planted in their area but only a fair idea of how different varieties might behave under alternative climatic and weather conditions and no information about the quality premiums/discounts likely to prevail during the marketing season. This, coupled with the relative lack of precision in the current 6-month forecasts (NOAA 2002), probably results in variety selection based on average or near-average May-September rainfall and heat-unit expectations and quality considerations only in reference to an average climate and premium/ discount environment.

The phosphorus application decision is already contingent on variety selection. Because phosphorus can be applied through the irrigation water at various times duting the first $8-10$ weeks of the season. knowledge of the rainfall and heat-unit accumulation during this period allows for some informed adjustment beyond the average climate expectation. A fully informed decision, however, would require precise rainfall and heat-unit forecasts for the 3 remaining months of the cotton-growing season. Also, producers might not be aware of the fact that the amount of phosphorus applied will interact with irrigation water/nitrogen, rainfall and heat-unit accumulation to affect all quality attributes.

Irrigation water may be periodically applied throughout the season, als needed, with some constraints imposed by $2-3$-week rotating irrigution schedules. Therefore, given the variety and the phosphorous tertilizer use decisions, it would appear that (quality aside) fully informed water/nitrogen application decisions might be attainable under precise 2week weather forecasts. However, many farms experience a limit in the amount of underground water that can be pumped per unit of tine. Thus, farmers often plant the maxinum crop area that can be properly irrigated under near-average rainfall and heat-unit conditions, and, during an unusually hot and dry season, they may not be able to irrigate as much as they would like. Therefore, a precise climatic forecast for the May-September period might be needed to achieve optimal irrigation water use during hot and dry growing seasons. Regarding quality, most producers are likely aware of the fact that the amount of irrigation water applied will affect at least some of the quality characteristics, and how (i.e., increase or decrease), but do not have the precise quantitative information required for fully optimal decision-making.

Increased quality considerations would be feasible given the availability of regionul-level yield and quality response models like the ones estimated in this study and of econometric models to predict the base price and the quality premiums/discounts that are likely to prevail during the cotton marketing season. On the other hand, it is clear that the perfect weather and climate information assumption is unattainable in the foreseeable future. Comparisons between a pessimistic scenario (decisions assuming average weather and climate) and a best-case scenario (decisions under perfect weather and climate information) help assess the potential magnitude of the effect of more reliable climate and weather information on the profitability and risk of irrigated cotton production in the Texas High Plains.

For the remainder of this article. the terms "quality considerations" and "no quality considerations" are used to mean that cotton quality is and is not being considered when making the protit-maximizing input-use decisions. Also, climate, which refers to periods longer than 2 weeks, will be used to mean both climate and weather, which refers to shorter time periods.

\section{Results and Discussion}

\section{The Estimated Yield and Qutality Models}

The parameter estimates for the final lint and seed yicld, turnout, micronaire. fiber strength, 
and staple length models are provided the Appendix. These models were reestimated to only include the variables that resulted statistically significant $(\alpha<0.20)$ in the initial models, according to two-tailed $t$ tests. The $\mathrm{i}$ nal lint yield model $\left(R^{2}=.687\right)$ includes second- and third-degree polynomials with respect to irrigation water/nitrogen and phosphorus, respectively, and a positive waterphosphorus interaction term. This results in a second-stage (i.c.. increasing at a decreasing rate) lint yield response to irrigation water/nitrogen and a neoclassical three-stage production response with respect to phosphorus. Within the sample data range, however, the marginal lint yield responses to the use of these three inputs are always positive. Both climate variables are found to affect lint yields directly and through three interaction terms. A few intercept and slope shifters account for differences in overall lint yield levels and on lint yield response to irrigation water/nitrogen and phosphorous fertilizer use across varieties.

The general features of the final seed yield model $\left(\mathrm{R}^{2}=.684\right)$ are similar to the lint yield model, as expected given the high .964 correlation between the lint and seed yield data. This model also includes second- and thirddegree polynomials with respect to irrigation water/nitrogen and phosphorus, respectively. and a positive water-phosphorus interaction term. Note that positive phosphorus- and heatunit-water interaction terms make up for the absence of at linear term on the water/nitrogen polynomial. As in the case of lint, the marginal seed yield responses to the use of these three inputs are always positive within the sample data range. Both climate variables are found to affect seed yields directly and through all of the four interaction terms included in the initial model. Several intercept and slope shifters accounting for differential effects across varieties remain in the final seed yield model as well.

The $\mathrm{R}^{2}$ values for the final turnout, micronaire, staple, and strength models are .414 , $.304, .371$, and .406 , respectively. Nonlinear, second-, or third-degree polynomial responses with respect to irrigation water/nitrogen use are found in the final micronaire, staple length. and fiber strength models, whereas nonlinear responses to phosphorus application are identitied in the final turnout and strength models. All models include direct linear responses to water/nitrogen and phosphorus or indirect linear responses through one or more interaction terms. In short. water/nitrogen and phosphorus use levels show statistically significant effects on all quality characteristics. Unlike the case of yields, however, some of the quality responses to additional use of certain inputs are negative or ambiguous in sign. This is illustrated in the following section. All four quality models identify statistically significant effects of the climatic variables and/or of interactions of these variables with the water/nitrogen and/ or phosphorus applicution levels. Several intercept and slope shifters accounting for differential effects across varieties remain in the final turnout. micronaire, staple, and strength models as well.

\section{Yield Response}

Under the assumption of long-term average rainfall $\left(9.5 \mathrm{in}\right.$.) and heat-unit $\left(1,270^{\circ} \mathrm{C}\right)$ accumulation. the model predicts substantial lint yield responses to both irrigation water and phosphorous fertilizer application at all input use levels, with maximum yields ranging from 1,225 lbs/acre (ADF Rocket) to 1,324 lbs/acre (Paymaster HS26 and Delta Pine 2156) at the highest irrigation water and phosphorus application rates evaluated. Extreme climate patterns substantially shift the lint yield response surfaces. Under high heat units $\left(1,500^{\circ} \mathrm{C}\right)$ and low rainfall ( $5 \mathrm{in.}$ ), the model predicts strong yield responses to irrigation water but weak to eventually negative responses to increased phosphorus application, especially at low water levels, and maximum lint yiefds only ranging from 985 to $1,084 \mathrm{lbs} / \mathrm{acre}$.

Under low heat-unit accumulation $\left(1,050^{\circ} \mathrm{C}\right)$ and high rainfall $(15 \mathrm{in}$.$) , the model$ predicts weak to eventually negative lint yield responses to irrigation water at the lowest phosphorous fertilizer application level and stronger but eventuatly plateauing responses to additional irrigation water as more phosphorus is applied. A climatic scenario pairing low 


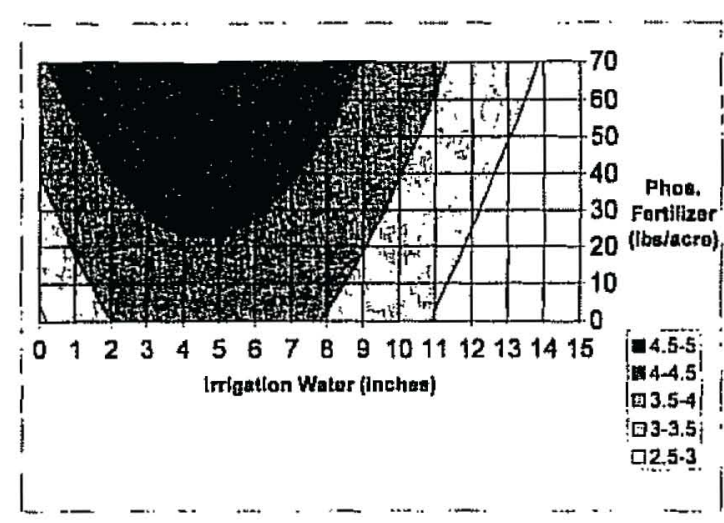

Figure 1. Predicted Micronaire Values for HOL338 under Average Rainfall and Heat Units

heat units $\left(1,050^{\circ} \mathrm{C}\right)$ and low rainfall $(5$ in.) results in worse overall lint yields, all under $700 \mathrm{lbs} / \mathrm{acre}$, whereas the best-case scenario is high heat units $\left(1.500^{\circ} \mathrm{C}\right)$ and rainfall $(15$ in.), with maximum yicld levels exceeding 1,800 lbs/acre. Although the previously discussed yield predictions are consistent with the experimental data used for model estimation, they are considerably higher than the yields observed in typical irrigated cotton production systems in the Texas High Plains (TASS). It is not unusual for experimental yields to be higher than on-farm yields. However, the lint and seed yield predictions utilized in the economic analyses were scaled down by a factor of 0.70 to obtain more realistic profit levels.

\section{Quality Response}

Nelson et al. estimated that micronatre values under 3.0 or over 5.0 produced substantial discounts of 3 cents/lb in 1999/2000 and of nearly 4 cents/lb during the $1998 / 1999$ nurketing season. At long-term average rainfall and heatunit accumulation, the micronalire response surfaces suggest that very low (2.5-3.0) micronaire values occur at high levels of irrigation water, regardless of the amount of phosphorus used (Figure 1). At the lint yieldmaximizing levels of $75 \mathrm{lbs}$ of phosphorus and 15 acre-inches of water. the predicted micronaire values range from 2.63 to 3.19 , depending on the variety. Regardless of phosphorus, at

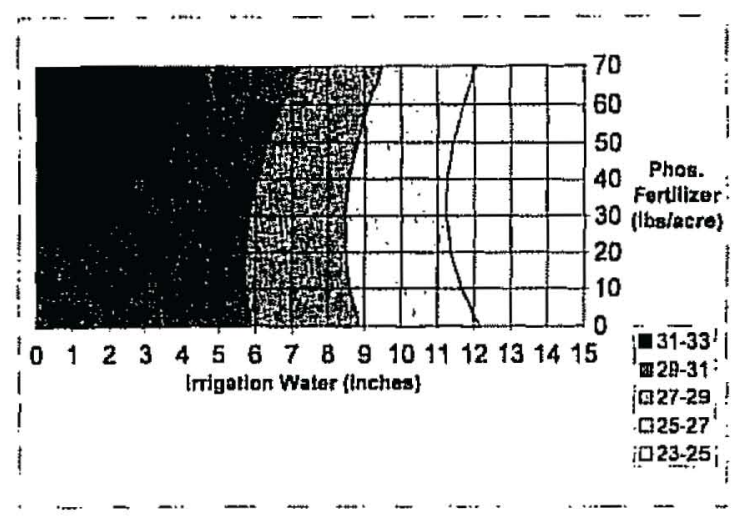

Figure 2. Predicted Strength Values for Paymaster HS26 under Average Rainfall and Heat Units

average rainfult and $1,050^{\circ} \mathrm{C}$ heat units, all varieties begin showing micronaire values below 3.5 after 9 or 10 acre-inches of irrigation water use. After 12 acre-inches, all varieties show predicted micronaire values under 3.0.

Nelson et al. also estimated that strength values under $23 \mathrm{~g} /$ tex produced discounts of 1-2 cents/lb, whereas strength readings over $27 \mathrm{~g} /$ tex resulted in premiums of $0.9-1.4$ cents/lb, depending on the season. Under average climate. the highest irrigation levels are predicted to result in the lowest strength values, ranging from 22 to $27 \mathrm{~g} / \mathrm{tex}$. whereas the lowest water application rates produce higher strength readings of between 28 and $35 \mathrm{~g} / \mathrm{tex}$, depending on the variety (Figure 2). At high irrigation water use levels, additional phosphorus only increases strength moderately, by $1-3 \mathrm{~g} /$ tex.

Regardless of heat units and phosphorus application, high rainfall (15 in.) broadens the range of predicted fiber strengths from under $21 \mathrm{~g} /$ tex at high water to over $35 \mathrm{~g} / \mathrm{tex}$ at low irrigation water use. Overall, the fiber strength model predicts that higher rainfall results in a broader range of fiber strength readings across the phosphorus-water use combinations evaluated and that higher heat units produce stronger cotton fiber at a rate of $0.3-0.6 \mathrm{~g} / \mathrm{tex}$ per 100 additional units.

Staple lengths from 0.95 to 1.03 in. result in price discounts ranging from 11 to 1 cents/ $\mathrm{lb}$, whereas lengths from 1.06 to $1.12 \mathrm{in}$. re- 


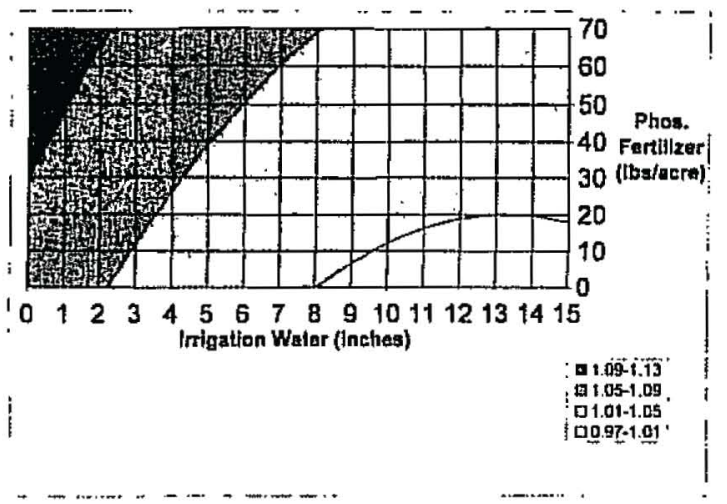

Figure 3. Predicted Staple Length Values for Paymaster Tejas under Average Rainfall and Heat Units

sulted in premiums ranging from 1 to 5 cents/ lb. depending on the season (Nelson et al.). Under the average rainfall and heat units, the lower staple length values predicted by the model range from 0.98 to 1.13 in., whereas the highest staple length values oscillate from 1.11 to 1.21 in., depending on the variety. The shorter fiber varieties in particular exhibit their lower staple values at high water and their highest staple lenglh at low irrigation water use levels (Figure 3). Low heat units $\left(1,050^{\circ} \mathrm{C}\right)$ and high rainfall (15 in.) shifts the cross-variety range of predicted staple length values from 0.88-1.05 in. at high water use and low phosphorus to $1.11-1.23 \mathrm{in}$. at low irrigation and high phosphorous fertilizer rates. Increased heat units $\left(1,500^{\circ} \mathrm{C}\right)$ result in even lower $(0.82-1.00$ in.) staple length values at high water and marginally higher (1.13-1.25 in.) readings at low water. Even at high $\left(1,500^{\circ} \mathrm{C}\right)$ heat units, however, at low rainfall (5 in.). most varieties present a narrower range of staple length values of between 1.05 and 1.25 in.

\section{Economic Analyses}

The estimated models show clear agronomic tradeoffs between yields and quality. In all of the climatic scenarios discussed above, the variety and input use combination that maximizes lint and seed yields is different from the combination that maximizes the premium (or, in the case of micronaire, minimizes the discount) received for any particular quality attribute (henceforth, the term premium will be used to imply either a positive or a negative premium-i.e., a (liscount). These agronomic tradeoffs, coupled with the strong climate and interaction effects identitied by the models, confirm the importance of conducting economic analyses of the impact of quality considerations and more accurate climate information on the profitability and risk of irrigated cotton production in the Texas High Plains.

Table 1 contains the average profits (Ave. $\Pi$ I), the lower $1 / 20$ percentile of profits (5\%LII), the average irrigation water use (Ave. W), the average phosphorous fertilizer use (Ave. P), the average total price per pound of lint yield (Tot. Price) (including premiums), and the average lint yield (Ave. LY) for each of the 11 varieties under the four quality/climate information scenarios discussed above. The averages are across the three quality premium (i.e., market) environments considered in the analysis. The Ave. $\Pi, 5 \% \mathrm{~L}$, Ave. W, and Tot. Price statistics are disaggregated by market environment in Table 2. All of these statistics are based on the 86 maximum profit levels attained by each of the varieties under the 86 historical rainfall-heat-unit combinations available for the analyses. The irrigation water and phosphorus use rates were limited to a maximum of 15 acre-inches and $75 \mathrm{lbs} /$ acre, to avoid out-of-sample forecasting.

As expected, improved climate information increases average protitability. regardless of the market environment or variety planted ( $\mathrm{Ta}$ ble 2). If cotton quality is ignored when making the (myopic) profit-maximizing witer and phosphorous fertilizer use decisions, on average for the 11 varieties across the three premium environments, improved climate information increases the 86-year average profits by $\$ 23.6 /$ acre $(63 \%)$ (Table 2). The average profit increatses are lowest (\$18.1/acre) under the market environment in the 1998/1999 season and highest (\$26.9/acre) under the 1997/ 1998 environment (Table 1). Under quality considerations, improved climate information increases overall average profits by $\$ 17.2 /$ acre 
Table 1. Average Profits (Ave. II), Lower 1/20 Percentile of Profits (5\%LII), Average Irrigation Water Use (Ave. W), Average Phosphorous Fertilizer Use (Ave. P.), and Total Price per lb of Lint Yield (Tot. Price) (including premiums/discounts) for 11 Varieties Across 86 Historical Climate/Weather Scenarios and Three (1997-99) Quality Premium/Discount Environments

\begin{tabular}{|c|c|c|c|c|c|c|}
\hline Variety & VI & V2 & V3 & V4 & V5 & V6 \\
\hline \multicolumn{7}{|c|}{$\begin{array}{l}\text { No Quality Considerations/Average Clinate and Weather Information, Year 1997/1998-1999/2000 Qua } \\
\text { ity Premium-Discount Environment }\end{array}$} \\
\hline Ave. II & 41.4 & 30.9 & 65.3 & 34.8 & 31.1 & 74.4 \\
\hline $5 \% L \Pi$ & -144.5 & -171.7 & -133.6 & -153.9 & -166.8 & -114.7 \\
\hline Ave. W & 15.0 & 14.3 & 15.0 & 15.0 & 14.7 & 12.0 \\
\hline Ave. P. & 75.0 & 75.0 & 75.0 & 75.0 & 75.0 & 75.0 \\
\hline Tot. Price & 0.547 & 0.553 & 0.558 & 0.544 & 0.560 & 0.579 \\
\hline Ave. LY & 955.4 & 903.1 & 960.1 & 939.6 & 900.4 & 919.5 \\
\hline
\end{tabular}

Quality Considerations/Average Climate and Weather Information. Year 1997/1998-1999/2000 Quality Premium-Discount Environment

$\begin{array}{lcccccc}\text { Ave. II } & 57.1 & 49.5 & 72.6 & 52.6 & 44.7 & 82.8 \\ \text { 5\%L.П } & -116.8 & -145.7 & -106.6 & -125.5 & -142.2 & -128.4 \\ \text { Ave. W } & 12.7 & 11.3 & 13.3 & 12.3 & 12.3 & 10.3 \\ \text { Ave. P. } & 75.0 & 75.0 & 75.0 & 75.0 & 75.0 & 75.0 \\ \text { Tot. Price } & 0.569 & 0.586 & 0.572 & 0.571 & 0.582 & 0.593 \\ \text { Ave. LY } & 912.4 & 858.6 & 934.0 & 892.3 & 868.1 & 900.0\end{array}$

No Quality Considerations/Perfect Climate and Weather Information, Year 1997/1998-1999/2000 Quality Premium-Discount Environment

$\begin{array}{lcccccc}\text { Ave. II } & 68.2 & 54.4 & 84.3 & 62.6 & 53.4 & 86.0 \\ \text { 5\%LII } & -115.5 & -154.5 & -106.6 & -123.6 & -147.9 & -127.7 \\ \text { Ave. W } & 13.9 & 13.5 & 14.2 & 13.9 & 13.7 & 12.0 \\ \text { Ave. P. } & 72.7 & 73.1 & 72.7 & 72.7 & 72.6 & 75.0 \\ \text { Tot. Price } & 0.564 & 0.567 & 0.570 & 0.563 & 0.573 & 0.579 \\ \text { Ave. LY } & 952.2 & 905.5 & 956.5 & 937.1 & 901.3 & 931.9\end{array}$

Quality Considerations/Perfect Climate and Weather Information, Year 1997/1998-1999/2000 Quality Premium-Discount Environment

\begin{tabular}{lcccccc} 
Ave. П & 76.5 & 64.6 & 91.3 & 71.7 & 61.5 & 94.0 \\
5\%LII & -112.0 & -139.6 & -103.4 & -118.5 & -139.0 & -109.0 \\
Ave. W & 12.6 & 11.8 & 13.0 & 12.4 & 12.3 & 10.8 \\
Ave. P. & 71.9 & 72.8 & 72.0 & 71.2 & 71.8 & 75.0 \\
Tot. Price & 0.578 & 0.587 & 0.582 & 0.578 & 0.588 & 0.593 \\
Ave. LY & 928.2 & 884.0 & 940.9 & 911.6 & 882.5 & 918.5 \\
\hline
\end{tabular}

$(33 \%)$. The smallest increase (\$15.5/acre) occurs under the 1998/1999 market environment.

Quality considerations also increase average profitability, regardless of the market environment or variety planted (Table 2 ). Under the average climate information scenario, on average for the 11 varieties across the three premium environments, quality considerations increase the 86-year average protits by $\$ 15.2 /$ acre $(41 \%)$. The average profit increases are lowest (\$5.7/acre) under the 1998/1999 market environment and highest ( $\$ 21.3 /$ acre) under the 1999/2000 environment (Table 1). Given perfect climate information, quality considerations increase the overall avernge profits by $\$ 8.8$ acre $(14 \%)$. The largest increase $(\$ 11.7 /$ acre) occurs under the $1999 / 2000$ premium environment. The combined effect of quality 
Table 1. (Extended)

\begin{tabular}{|c|c|c|c|c|c|c|}
\hline v7 & V8 & V9 & $\mathrm{V} 10$ & V1I & Ave. & Best \\
\hline 28.8 & 36.0 & 21.5 & 0.1 & 46.8 & 37.4 & - \\
\hline-169.3 & -157.0 & -162.8 & -208.2 & -139.9 & -156.6 & - \\
\hline 15.0 & 15.0 & 14.0 & 14.3 & 13.7 & 14.4 & - \\
\hline 75.0 & 75.0 & 75.0 & 75.0 & 75.0 & 75.0 & - \\
\hline 0.549 & 0.560 & 0.562 & 0.532 & 0.564 & 0.555 & - \\
\hline 928.5 & 930.5 & 877.1 & 888.6 & 913.1 & 919.6 & - \\
\hline 46.4 & 50.2 & 34.4 & 27.6 & 61.0 & 52.6 & - \\
\hline-135.4 & -128.1 & -152.0 & -170.7 & -131.9 & -134.8 & - \\
\hline 12.3 & 12.7 & 12.0 & 11.0 & 11.3 & 12.0 & - \\
\hline 75.0 & 75.0 & 75.0 & 75.0 & 75.0 & 75.0 & - \\
\hline 0.576 & 0.580 & 0.582 & 0.579 & 0.586 & 0.580 & - \\
\hline 878.3 & 887.5 & 849.9 & 835.8 & 883.9 & 881.9 & - \\
\hline 57.7 & 62.1 & 45.5 & 27.2 & 69.9 & 61.0 & - \\
\hline-130.6 & -127.5 & -156.7 & -185.2 & -139.0 & -137.7 & - \\
\hline 13.8 & 13.8 & 13.2 & 13.4 & 13.0 & 13.5 & - \\
\hline 71.5 & 72.2 & 72.4 & 72.0 & 71.6 & 72.6 & - \\
\hline 0.568 & 0.576 & 0.575 & 0.550 & 0.575 & 0.569 & - \\
\hline 924.8 & $y 25.2$ & 881.8 & 891.3 & 921.0 & 920.8 & - \\
\hline 66.7 & 68.7 & 52.1 & 43.3 & 77.8 & 69.8 & 103.2 \\
\hline-121.3 & -123.6 & -1.46 .5 & -160.7 & -123.2 & -127.0 & -102.0 \\
\hline 12.3 & 12.6 & 11.9 & 11.2 & 11.6 & 12.1 & 11.8 \\
\hline 69.6 & 71.9 & 71.7 & 71.1 & 71.3 & 71.8 & 71.8 \\
\hline 0.584 & 0.588 & 0.588 & 0.581 & 0.590 & 0.585 & 0.591 \\
\hline 898.6 & 904.8 & 863.5 & 859.5 & 903.3 & 899.6 & 931.7 \\
\hline
\end{tabular}

considerations and perfect climate information, in comparison to the no quality considerations/average clinate information scenario, is an overall increase in average protitability of $\$ 32.4 /$ acre $(87 \%)$, ranging from $\$ 19.6$ to $\$ 43.2$ acre across varieties and from $\$ 21.4$ to $\$ 38.2$ acre across marketing years.

As to risk, on average for the 11 varieties across the three premium environments, per- fect climate information increases the $1 / 20$ protit percentile from $-\$ 156.6 /$ acre to $-\$ 137.7 /$ acre, given a lack of yuality considerations, and from $-\$ 134.8$ /acre to $-\$ 127.0 /$ acre when profits are maximized with regard to both quantity and quality (Table 1). That is. the effect of improved climate information on downside profit risk is substantially more pronounced if cotton quality is ignored when 
Table 2. Average Profits (Ave. П), Lower 1/20 Percentile of Profits (5\%LП), Average Irrigation Water Use (Ave. W), and Total Price per lb of Lint Yield (Tot. Price) (including premiums/discounts) for 11 Varieties Across 86 Historical Climate/Weather Scenarios, under the 1999, 1998. and 1997 Quality Premium/Discount Environments

\begin{tabular}{lcccccc}
\hline Variety & V1 & V2 & V3 & V4 & V5 & VG \\
\hline No Quality Considerations/Average Climate and & Weather Information, Year & 1999/2000 Quality Premium- \\
Ditcount Environment & & & & & \\
Ave. II & -36.9 & -25.5 & -6.1 & -40.7 & -23.2 & 15.0 \\
5\%Lll & -202.0 & -212.3 & -196.0 & -211.0 & -203.3 & -154.4 \\
Ave. W & 15.0 & 14.0 & 15.0 & 15.0 & 14.0 & 12.0 \\
Tot. Price & 0.469 & 0.490 & 0.486 & 0.467 & 0.500 & 0.515
\end{tabular}

Quality Considerations/Average Climate and Weather Information, Year 1999/2000 Quality PremiumDiscount Environment

$\begin{array}{lcccccc}\text { Ave. II } & -8.8 & -4.3 & 7.1 & -12.4 & -9.5 & 25.5 \\ \text { 5\%LII } & -160.7 & -182.7 & -150.8 & -166.7 & -179.7 & -167.7 \\ \text { Ave. W } & 12.0 & 11.0 & 13.0 & 12.0 & 12.0 & 10.0 \\ \text { Tot. Price } & 0.503 & 0.526 & 0.505 & 0.502 & 0.522 & 0.531\end{array}$

No Quality Considerations/Perfect Climate and Weather Information, Year 1999/2000 Quality PremiumDiscount Environment

$\begin{array}{lcccrrr}\text { Ave. IT } & -0.8 & -4.1 & 19.2 & -4.8 & -4.8 & 23.8 \\ 5 \% \text { LI } & -161.1 & -202.9 & -152.5 & -166.0 & -193.3 & -166.9 \\ \text { Ave. W } & 13.7 & 13.3 & 14.0 & 13.7 & 13.5 & 11.7 \\ \text { Tot. Price } & 0.493 & 0.502 & 0.503 & 0.492 & 0.509 & 0.514\end{array}$

Quality Considerations/Perfect Climate and Weather Intormation, Year 1999/2000 Quality Premium-Discount Environment

$\begin{array}{lcccccc}\text { Ave. } \Pi & 10.9 & 8.6 & 28.9 & 7.1 & 5.9 & 35.0 \\ \text { 5\%LIT } & -155.4 & -178.1 & -146.8 & -159.5 & -177.7 & -147.0 \\ \text { Ave. W } & 12.1 & 11.4 & 12.6 & 12.1 & 12.0 & 10.7 \\ \text { Tot. Price } & 0.511 & 0.527 & 0.518 & 0.511 & 0.528 & 0.531\end{array}$

No Quality Considerations/Average Climate and Weather Information. Year 1998/1999 Quality PremiumDiscount Environment
Ave. $\Pi 1$
$64.4 \quad 52.1$
$5 \% \mathrm{LIl}$
$-104.6$
$-126.9$
82.0
$-94.0$
59.0
45.2
83.9
Ave. W
15.0
14.0
15.0
$-112.1$
$-132.1$
$-104.7$
Tot. Price
0.570
0.577
0.575
15.0
15.0
12.0
$0.569 \quad 0.576$
0.590

Quality Considerations/Average Climate and Weather Information, Year 1998/1999 Quality PremiumDiscount Environment
Ave. II
70.4
57.1
$5 \%$ LII
$-106.0$
$-132.7$
83.5
$-92.9$
65.8
52.3
87.3
Ave. $W$
13.0
12.0
14.0
$-112.6$
$-129.9$
$-115.2$
Tol. Price
0.581
0.590
0.580
0.580
13.0
11.0

No Quality Considerations/Perlect Climate and Weather Information. Year 1998/1999 Quality PremiumDiscount Environment
Ave. 11
83.3
68.0
$-128.8$
95.7
$-90.0$
78.8
$-107.0$
64.9
-126.6
95.6
Ave. $W$
13.9
1.3 .5
14.2
13.9
13.7
$-107.2$
Tot. Price
0.580
0.584
0.583
0.580
0.587
12.0
$0.590)$ 
Table 2. (Extended)

\begin{tabular}{|c|c|c|c|c|c|c|}
\hline V7 & V8 & Vy & V10 & $\mathrm{V} 11$ & Ave. & Best \\
\hline-38.5 & -31.5 & -38.9 & -59.7 & -7.8 & -26.7 & - \\
\hline-223.8 & -21.3 .7 & -212.0 & -257.8 & -175.5 & -205.6 & - \\
\hline 15.0 & 15.0 & 14.0 & 14.0 & 13.0 & 14.2 & - \\
\hline 0.479 & 0.490 & 0.494 & 0.464 & 0.505 & 0.487 & - \\
\hline-12.0 & -7.6 & -18.3 & -25.7 & 6.0 & -5.4 & - \\
\hline-173.9 & -168.1 & -192.7 & -215.5 & -169.1 & -175.2 & - \\
\hline 12.0 & 12.0 & 11.0 & 10.0 & 11.0 & 11.5 & - \\
\hline 0.513 & 0.520 & 0.526 & 0.523 & 0.526 & 0.518 & - \\
\hline-3.6 & 1.2 & -10.3 & -35.1 & 11.3 & -0.7 & - \\
\hline-172.2 & -169.9 & -198.2 & -2.34 .5 & -177.8 & -181.4 & - \\
\hline 13.6 & 13.6 & 13.0 & 13.2 & 12.8 & 13.3 & - \\
\hline 0.50 .3 & 0.511 & 0.512 & 0.479 & 0.513 & 0.503 & - \\
\hline 8.2 & 10.4 & -2.1 & -13.2 & 21.7 & 11.0 & 42.5 \\
\hline-1.57 .7 & -16.3 .4 & -182.0 & -197.3 & -159.1 & -165.8 & -143.3 \\
\hline 12.0 & 12.3 & 11.6 & 10.5 & 11.2 & 11.7 & 11.5 \\
\hline 0.522 & 0.526 & 0.528 & 0.521 & 0.530 & 0.523 & 0.528 \\
\hline 49.4 & 52.8 & 36.1 & 30.3 & 58.8 & 55.8 & - \\
\hline-124.6 & -117.8 & -136.9 & -150.1 & -117.7 & -120.1 & - \\
\hline 15.0 & 15.0 & 14.0 & 14.0 & 14.0 & 14.4 & - \\
\hline 0.571 & 0.577 & 0.578 & 0.568 & 0.577 & 0.575 & - \\
\hline 56.3 & 58.6 & 40.3 & 38.3 & 66.8 & 61.5 & - \\
\hline-122.7 & -119.1 & -139.0 & -151.1 & -120.8 & -122.0 & - \\
\hline 13.0 & 13.0 & 13.0 & 12.0 & 12.0 & 12.6 & - \\
\hline 0.583 & 0.587 & 0.584 & 0.584 & 0.589 & 0.586 & - \\
\hline 70.8 & 72.2 & 55.0 & 49.0 & 80.0 & 73.9 & - \\
\hline-117.4 & -112.5 & -138.1 & -152.1 & -120.6 & -118.1 & - \\
\hline 13.8 & 13.8 & 13.3 & 13.4 & 13.0 & 13.5 & - \\
\hline 0.583 & 0.587 & 0.587 & 0.577 & 0.587 & 0.584 & - \\
\hline
\end{tabular}


Table 2. (Continued)

\begin{tabular}{lcccccc}
\hline Variety & V1 & V2 & V3 & V4 & V5 & V6 \\
\hline $\begin{array}{l}\text { Quality Consideratinns/Perfect Climate and Weather Inforn } \\
\text { count Environment }\end{array}$ & & & & & & \\
Ave. II & 86.7 & 71.8 & 98.6 & 82.4 & 67.9 & 98.5 \\
5\%LII & -99.2 & -125.8 & -90.0 & -106.9 & -125.7 & -102.0 \\
Ave. W & 13.0 & 12.5 & 13.4 & 12.9 & 12.8 & 11.2 \\
Tot. Price & 0.586 & 0.591 & 0.588 & 0.587 & 0.593 & 0.596
\end{tabular}

No Quality Considerations/Average Climate and Weather Information, Year 1997/1998 Quality PremiumDiscounı Environment

$\begin{array}{lcccccc}\text { Ave. II } & 96.6 & 60.0 & 120.1 & 86.2 & -71.3 & 124.4 \\ \text { 5\%LlI } & -127.0 & -175.9 & -110.8 & -138.7 & -165.0 & -85.0 \\ \text { Ave. W } & 15.0 & 15.0 & 15.0 & 15.0 & 15.0 & 12.0 \\ \text { Tol. Price } & 0.603 & 0.592 & 0.614 & 0.597 & 0.603 & 0.633\end{array}$

Quality Considerations/Average Climate and Weather Information, Year 1997/1998 Quality PremiumDiscount Environment

$\begin{array}{lcccccc}\text { Ave. II } & 109.7 & 95.7 & 127.1 & 104.3 & -91.4 & 135.5 \\ \text { 5FLil } & -83.7 & -121.6 & 76.0 & -97.2 & -117.0 & -102.3 \\ \text { Ave. W } & 13.0 & 11.0 & 13.0 & 12.0 & 12.0 & 10.0 \\ \text { Tot. Price } & 0.623 & 0.643 & 0.632 & 0.630 & 0.638 & 0.653\end{array}$

No Quality Considerations/Perfect Climate and Weather Information, Year 1997/1998 Quality PremiumDiscount Environment

$\begin{array}{lcccccc}\text { Ave. II } & 122.0 & 99.4 & 138.1 & 113.9 & 100.0 & 138.5 \\ 5 \% \text { II } & -86.1 & -131.9 & -77.4 & -97.7 & -123.9 & -108.9 \\ \text { Ave. W } & 14.0 & 13.6 & 14.3 & 14.0 & 13.8 & 12.2 \\ \text { Tot. Price } & 0.619 & 0.615 & 0.625 & 0.616 & 0.623 & 0.633\end{array}$

Quality Considerations/Perfect Climate and Weather Information, Year 1997/1998 Quality Premium-Discount Environment

\begin{tabular}{lcccccc} 
Ave. II & 131.8 & 113.4 & 146.5 & 125.7 & 110.8 & 148.5 \\
5\%LII & -81.5 & -115.0 & -73.3 & -89.2 & -113.6 & -78.1 \\
Ave. W & 12.6 & 11.6 & 13.0 & 12.3 & 12.2 & 10.6 \\
Tot. Price & 0.636 & 0.642 & 0.641 & 0.637 & 0.644 & 0.652 \\
\hline
\end{tabular}

making inpul-use decisions. Also on the average, under the average climate information scenario, yuality considerations increase the $1 / 20$ profit percentile from $-\$ 156.6 /$ acre to $-\$ 134.8 /$ acre and from $-\$ 137.7 /$ acre to $-\$ 127 / a c r e$ when availability and use of perfect climate information are assumed.

The combined effect of quality considerations and perfect climate information is an overall decrease in downward profit risk of $\$ 29.6 /$ acre $(19 \%)$, ranging from $\$ 5.7 /$ acre to $\$ 48 /$ acre across varieties and from $\$ 4.1 /$ acre to $\$ 44.8$ acre across market environments, which suggests that the degree risk reduction varies widely depending on the variety planted and on the prevailing market conditions. Regardless, it is clear that even under this most optimistic scenario, cotton production in the Texas High Plains remains subject to a substantial level of climate-related risk.

When profits are maximized without regard to quality, perfect climate information reduces optimal irrigation water use across all market environments evaluated and all but one of the varieties in the analysis, from an average of 14.4 to $13.5 \mathrm{in}$. The cross-variety average reduction $(0.9 \mathrm{in}$.) is the same under all three premium environments evaluated (Table 2 ). Given quality considerations, however, perfect climate information does not show a substan- 
Brift, Remires, and Carpis: Quality, Weather, and Cotton Production

Table 2. (Continued) (Extended)

\begin{tabular}{|c|c|c|c|c|c|c|}
\hline V7 & V8 & V9 & V10 & V11 & Ave. & Best \\
\hline 74.3 & 74.7 & 57.5 & 54.4 & 82.9 & 77.2 & 108.0 \\
\hline-114.4 & -112.5 & -1.36 .1 & -147.0 & -115.9 & -116.0 & -90.0 \\
\hline 12.8 & 13.0 & 12.4 & 12.0 & 12.1 & 12.6 & 12.1 \\
\hline 0.590 & 0.592 & 0.592 & 0.588 & 0.593 & 0.590 & 0.594 \\
\hline 75.6 & 86.6 & 67.4 & 29.6 & 89.4 & 83.0 & - \\
\hline-159.6 & -1.39 .6 & -1.39 .4 & -216.8 & -126.5 & -144.0 & - \\
\hline 15.0 & 15.0 & 14.0 & 15.0 & 14.0 & 14.5 & - \\
\hline 0.598 & 0.612 & 0.613 & 0.565 & 0.609 & 0.60 .3 & - \\
\hline 94.9 & 99.7 & 81.2 & 70.3 & 110.2 & 101.8 & - \\
\hline-109.6 & -97.2 & -124.4 & -145.5 & -105.9 & -107.3 & - \\
\hline 12.0 & 13.0 & 12.0 & 11.0 & 11.0 & 11.8 & - \\
\hline 0.633 & 0.632 & 0.636 & 0.629 & 0.644 & 0.636 & - \\
\hline 105.9 & 112.8 & 91.7 & 67.7 & 118.3 & 109.9 & - \\
\hline-102.2 & -100.0 & -1.33 .8 & -168.9 & -118.7 & -113.6 & - \\
\hline 13.9 & 13.9 & 13.4 & 13.6 & 13.2 & 13.6 & - \\
\hline 0.618 & 0.629 & 0.626 & 0.59 .3 & 0.626 & 0.620 & - \\
\hline 117.6 & 121.1 & 101.0 & 88.6 & 128.7 & 121.2 & 159.0 \\
\hline-91.8 & -95.0 & -121.5 & -137.9 & -94.6 & -99.2 & -72.8 \\
\hline 12.2 & 12.6 & 11.8 & 11.0 & I 1.4 & 11.9 & 11.7 \\
\hline 0.641 & 0.645 & $0.6+4$ & 0.634 & 0.646 & 0.642 & 0.650 \\
\hline
\end{tabular}

tial effect on irrigation water use on the average or for particular varieties or market environments (Tables 1 and 2).

Quality considerations, on the other hand, result in substantial reductions in irrigation water use, regardless of the climate information scenario being assumed. The average reduction across varieties and premiun regimes is from 14.4 to $12.0 \mathrm{in}$. under average information and from 13.5 to 12.1 in. under perfect climate information (Table 1). The magnitudes of these reductions are fairly consistent across varieties and market environments (Table 2).

With regard to the previously discussed concern about an overestimation of the $M P P_{W}$. at high rainfall levels, note that this 12.1 acre- inch 86-year avernge optimal irrigation water is lower than the observed average use of about 15 in. in the Texas High Plains (Johnson and Segarra). Under the quality considerations/perfect climate information scenario, optimal water use only reaches the enforced 15 -in. limit 6 out of 86 years and at very low rainfall levels of between 3.9 and 7.1 acreinches, for an average total (rainfall plus irrigation) water use of 21.6 in. At the six highest rainfall levels observed, ranging from 14.9 (o) 22.4 in. optimal irrigation water use only averages $8.8 \mathrm{in.}$ and total (rainfall plus imigation) water averages 26.6 in., in comparison with the commonly recommended total water use of 25-30 in. (Johnson and Segarra). In 
short, it appears that the estimated models are well calibrated, because they result in reasonable optimal irrigation levels within the observed range of rainfall.

The fact that quality considerations could notably decrease irrigation water use is a relevant empirical finding for the Texas High Plains, where water is pumped from the southern tip of the Ogallala Aquifer. The saturated thickness level of this section of the aquifer has decreased substantially during the past 50 years because of increased irrigated crop production combined with sparse rainfall and a limited recharge capability. Although more efficient irrigation technologies have helped stabilize the rate of decline during the 1980s and 1990s, aquifer depletion continues to be a major concern for the regional agricultural industry and local and state policy makers (Stovall. Rainwater, and Frailey). At the most recent irrigated cotton plantings of about 2 million acres (TASS), a 2.5 acre-inch overall reduction in irrigation water use would save $5 \mathrm{mil}$ lion acre-inches per season, in comparison to the estimated year 2000 net rate of aquifer depletion of 12.9 million acre-inches (Stovall. Rainwater, and Frailey).

In contrast. quality considerations do not affect phosphorus application rates under the average climate information scenario and, given perfect information, only reduce them from the allowed maximum of $75 \mathrm{lbs} / \mathrm{acre}$ by an overall average of $0.8 \mathrm{lbs} / \mathrm{acre}(1.1 \%)$ (Table 1). The availability and use of perfect versus average climate information results in higher, but still minor, overall average reductions in phosphorus application of 3.2 and $2.4 \mathrm{lbs} / \mathrm{acre}$ under quality and no quility considerations.

As expected, quality considerations substantially increase the premiums across all varieties and market environments evaluated, resulting in higher total prices. Under the average climate information scenario, the total price increases average 2.5 cents/b (4.5\%) and range from 1.4 to 4.7 cents/lb across varieties and from to 1.1 cents/lb to $3.3 \mathrm{cents} / \mathrm{lb}$ depending on the market environment. Under the perfect climate information scenario, the total price increases average 1.6 cents/lb $(2.8 \%)$ and range from 1.2 to 3.1 cents/lb across varieties and from 0.6 cents/lb to 2.2 cents/lb depending on the market environment.

These relatively pronounced premium increases mean that a markedly higher quality of cottion would be produced in the Texiss High Plains, which historically accounts for about 20\% of U.S. production. This would benefit High Plains farmers and the entire U.S. cotton industry as well. Perfect climate information increases the overall average price by 1.4 cents/lb $(2.5 \%)$ under no quality considcrations and by 0.5 cents $/ \mathrm{lb}(0.9 \%)$ when quality is taken into account in the profit-maximizing input use decisions, which suggests a moderate increase in the cluality of the cotton produced. Also as expected. profit maximization under quality considerations results in 10-60 lbs/acre lower average lint yields across all of the varieties and market environments evaluated (Table 2). At yields averaging from about $800-1000 \mathrm{lbs} / \mathrm{acre}$, the previously discussed total price increases coupled with the $\$ 10 /$ acre to $\$ 15 /$ acre cost savings from reduced irrigation water offset these lint yield reductions and explain the previously discussed gains in average profitability due to quality considerations.

Interestingly, under no quality considerations, perfect climate information only shows a minimal positive effect on overall average lint yieids (Table 2), which is ambiguous in sign across the 11 varieties evaluated. Given quality considerations, the effect is unambiguously positive across all varieties and market environments evaluated but still moderate in mugnitude (17.7 Jbs/acre, 2\%).

The economic analyses aiso suggest that variety selection is important and that it interacts with quality considerations and climate information. Regardless of the marketing environment and of the quality considerutions/ climate information scenario being assumed, appropriate variety selection substantially increases average profitability and reduces risk in comparison to the cross-variety averages and even more drastically in relation to the worse performing varieties.

Under the 1999/2000 market environment and the baseline scenario of no quality consid- 
erations/average information, HOL 338 (V6) produces substantially higher 86-year average protits $(\$ 15 / \mathrm{acre})$ and lower risk $(5 \% \mathrm{LlI}=$ $-\$ 154.4 /$ acre) than all other varieties (Table 2). Given quality considerations/average climate information. HOL 338 still produces the highest average profits. which are increased to $\$ 25.5 / a c r e$, but risk is also increased (5\% LI $=-\$ 167.7 /$ acre). Delta Pine 2156 (V3) presents the second highest average protits (\$7.1/ acre) and the lowest risk measure $(5 \% \mathrm{LII}=$ $-\$ 150.8$ / acre). Irrigation water use is reduced by 2 acre-inthes, and the total price increased by $1.9(\mathrm{~V} 3)$ and $1.6(\mathrm{~V} 6)$ cents/lb.

Under the ideal quality considerations/perfect climate information scenario, both $\mathrm{HOL}$ 338 and Delta Pine 2156 show still higher average protitability ( $\$ 35 /$ acre and $\$ 28.9 /$ acre) and lower, nearly identical risk measures $(5 \% \mathrm{LII}=-\$ 147 / \mathrm{acre}$ and $5 \% \mathrm{LII}=-\$ 146.8 \mathrm{I}$ acre). Other varieties. however, produce higher protits during some of the 86 rainfall-heat-unit combinations used in the analysis. Therefore, given perfect climate information, it would be possible to further increase average profits to $\$ 42.5 /$ acre by planting the variety that will perform best under the predicted climate. Average irrigation water use would be 11.5 acreinches and total price 52.8 cents/lb versus the cross variety average of 14.2 in. and 48.7 cents/lb under the baseline no quality considerations/average climate information scenario.

Similar results are observed under the 1997/1998 premium environment (Table 2). Comparison of the baseline to the quality considerations/average climate information scenario reveals significant average profit increuses for both HOL 3.38 and Delta Pine 2156 (from \$124.4/acre and \$120.1/acre, to \$135.5/ acre and 127.1/acre), the development of a risk-return tradeoff $(5 \% \mathrm{LI}=-\$ 102.3 /$ acre vs. $5 \%$ LII $=-\$ 76.0 /$ acre), a 2 acre-inch reduction in irrigation water use, and substantially ( 1.8 cents/lb and 2.0 cents/lb) higher total prices.

Additional average profit increases (to $\$ 148.5 /$ acre and $\$ 146.5 /$ acre) and risk measure decreases are found under the ideal quality considerations/perfect climate information scenario. The "best-performing" variety sce- nario produces still higher average profits of $\$ 159 /$ acre and the lowest possible risk (5\%LII $=-\$ 72.8 / \mathrm{acre})$ at an average irrigation water use of $11.7 \mathrm{in}$. and total price of 65.0 cents/ $\mathrm{lb}$, in comparison to a cross-variety average of 14.5 in. and 60.3 cents/lb under the baseline scenario.

Under the quality premium environment prevailing during the 1998/1999 marketing season, however, Delta Pine 2156 could be preferred to HOL 338 on the basis of similar average profits but consistently lower risk measures. Under either variety, quality considerations only show marginal increases in average profitability and little impact on risk. Irrigation water use is still decreased but by less than $I$ in., on average, whercas the total price only increases by $0.5-0.6$ cents/lb. However, because of the effect of improved weather information, both of these varieties show substantially higher average profitability ( $\$ 98.6 /$ acre and $\$ 98.5 /$ acre) and marginally lower risk under the quality considerations/perfect weather information scenario than under the baseline $(\$ 82.2 /$ acre and $\$ 83.9 /$ acre). Water use is reduced by 1.6 and $0.8 \mathrm{in}$., whereas price increases by 1.3 and 0.6 cents/lb. The "best-performing" variety scenario yields still higher average profits of $\$ 108$ /acre and the lowest possible risk ( $5 \% \mathrm{L \Pi}=-\$ 90.0 / \mathrm{acre})$ at an average irrigation water use of $12.1 \mathrm{in}$. and total price of 59.4 cents $/ \mathrm{lb}$, in comparison to a cross-variety average of $14.4 \mathrm{in}$. and 57.5 cents/lb in the baseline scenario.

Two final comments about the previously discussed results are in order. First, the profit levels reported above are subject to the average $(800-950 \mathrm{lbs} / \mathrm{acre})$ yields entering the analysis. Many farms in the Texas High Plains do not attuin such high average yield levels. Nevertheless, the differences in the estimated profits across the scenarios evaluated should be generally indicative of what would happen at somewhat different yield levels. Second, the measures of risk are only in relation to yield variability caused by climate uncertainty, which is one of the main concerns of this study. These measures underestimate the actual level of downward profit variation experienced by cotton producers, which is exacer- 
bated by other sources of yield variability as well as by price uncertainty.

\section{Concluding Remarks}

A main contribution of this research is to quantify the impact of irrigation water/nitrogen and phosphorous fertilizer use on the three major cotton lint quality attributes. The predicted differences in quality resulting from changes in variety selection, water/nitrogen and phosphorous fertilizer use. or the prevailing climate are large enough to trigger considerable premiums under the current cotton pricing system. Substantial agronomic management tradeofts between lint yields and quality are also identified. Theoretically, it is clear that profit maximizing variety and input use decisions incorporating quality considerations and perfect climate information should increase profitability and reduce risk as measured in this study. The question is whether the expected profit increases and risk reductions due to quality considerations and/or to the availability and use of improved climate information could be substantial in practice. Another important question is the potential effect of quality considerations and climate information on irrigation water use and the quality of the cotton produced.

It is concluded that, on average, under the three most recent marketing season base price and quality premium/discount environments and 11 varieties that are commonly planted in the Texas High Plains, quality considerations could have an empirically meaningful impact on increasing profitability and reducing climate-related risk, regardless of the climate information availability/use assumption. They would also result in considerably lower levels of irrigation water use and a markedly higher quality in the cotton produced. These changes, however. are measured from a baseline of no quality considerations. In practice, producers might already be making some experiencebased quality considerations in their variety and input-used decisions. Also (on average), it is concluded that the availability and use of improved climate information for making variety and input use decisions could substan- tially increase profitability and reduce risk, regardless of the quality consideration assumption.

The impact of improved climate information on irrigation water use and cotton quality is predicted to be relatively small. Again, this is from a baseline of decision-making that assumes long-term average climate versus actual climate (i.e., perfect climate information). In practice, farmers probably plan for the average but adjust input use (particularly irrigation water) throughout the season depending on the observed weather. In addition, although quite accurate 1-2-week weather forecasts are feasible, perfect climate forecasts are unlikely in the foreseeable future. Nevertheless, the results of this study indicate that quality considerations and the availability and use of improved climatic and weather information for variety and input use decisions through profitmaximizing production economics models that involve marketing season price and premium/ discount predictions could be an important element in the more efficient precision-managed cotton production systems of the future, which would be needed to maintain the competitiveness of U.S. agriculture.

A final note of caution about the models estimated in this study: although the models and related inferences are statistically sound, they are based on 3 years of experimental data from Lubbock County. The yield and quality predictions from these models are imperfect because of the usual "random" error-i.e., the effect of factors not included in the models. When applied in farm management decisions, the predictions would also be subject to "extrapolation" error caused by any major difference between the experimental site/management and the farm site/management. Reestimating the models on the basis of an expanded data set that includes future-year $o b-$ servations from other Texas High Plains cotton-farming areas could reduce this extrapolation error. Similar models could be estimated and eventually used for farm-level decision making in the other three major cotton-producing areas of the United States.

[Received July 2001; Accepted May 2002.] 


\section{References}

Beach, E.D., and G.A. Carlson. "A Hedonic Analysis of Herbicides: Do User Safety and Water Quality Matter." American Joumal of Agricultural Ecomomics 75(1993):612-23.

Bradow, J.M., and G.H. Davidonis. "Quantification of Fiber Quality and the Cotton Production-Processiong Interface." Joumal of Cotm Science $4(2000): 34-64$.

Chiou, G.T., D.T. Chen, and O. Capps. "A Struetural Investigmion of Biolechnological Impacts on Cotton Quality and Returns." American Joumal of Agricultural Economics 75(1993): 467-78.

Ethridge, D., and D. Hudson. "Cotton Price Information: How It Affects the Industry." Joumal of Cotton Scienc' 2(1998):68-76.

Faux, J., and G.M. Perry. "Estimating Irrigation Water Value Using Hedonic Price Analysis: A Cuse Study in Malheur County, Oregon." Land Economic:s 75(1999):440-52.

Green, C.J.. D.R. Krieg, and J.S. Reiter. "Cotton Response to Multiple Applications of Nutrient Mixtures." Biltwide Cotton Conferences Proceedings, Orlando, FL, 1999, pp. 1272--73.

Hansen, L. "Farmer Response to Changes in Climate: The Case of Corn Production." Jotmal of Agricullural Economics Research 43(1991): $18-27$.

High Plains Water Conservation District. "An Analysis of Irrigation Ditch Losses, Pump Plants, and the Cost of Pumping Water." Report 98-1, Lubbock, TX. 1998.

Hudson. D., D. Ethridge, and E. Segarra. "Incurrect Price Information for a Heterogeneous Commodity: A Conceptual Synthesis." Review of Agricultural Eionomics 20(1998):363-74.

Johnson, P., and E. Segarra. Personal Communication. Department of Agricultural and Applied Economics, Texas Tech University. February 2002.

Kaufmann, R.K., and S.E. Snell, "A Biophysical Model of Corn Yield: Integrating Climatic and Social Determinants." American Jenurnal of Agriculural Ecromomics 79(1997): 178-90.
Krieg, D.R. Personal Communication. Department of Plant and Soil Sciences, Texas Tech University, October 2001 .

Mjelde, J.W., S.T. Sonka. B.L. Dixon, and P.J. Lamb. "Valuing Forecast Characteristics in a Dynamic Production System." American Journal of Agricultural Ecomonics 70(1988):674 84.

Morrow, M., and D.R. Krieg. "Cotton Management Strategies for a Short Growing Season Environment: Water-Nitrogen Considerations." Agromrmy Journal 84(1990):52-56.

National Ocennic and Atmospheric Administration. Internet site: http:/www.cpc.noaa.gov/ (Accessed March 4, 2002).

- Min/Max Temperature at the Lubbock International Airport Weather Station from 19141999. Data ubtained from the National Climatic Data Center, Asheville, NC, January 2001.

National Weather Service. Lubbock Precipitation from 1911-1999. Data obtained from the Weather Bureau of Lubbock, TX, January 2001.

Nelson, J., K. Hoelscher, S. Misra, and D. Ethridge. Texas-Oklahoma Prodicer Coston Market Summary: 1999/00. Cotton Economics Research Report CER-00-16, Department of Agricultural and Applied Economics, Texas Tech University. September 2000.

Parker. D.D., and D. Zilberman. "Hedonic Estimation of Quality Factors Affecting the FarmRetail Margin." American Journal of Agricultural Economics 75(1993):458-66.

Phillips L. Personal Communication. National Weather Service. Lubbock, TX. March 2002.

Seratin, R.J., and J.W. Wilson. "Operational Weathcr Radar in the United States: Progress and Opportunity." Bulletin of the American Metenrological Society 81(2000):50)]-18.

Stovall, J., K. Rainwater, and S. Frailey. Ground Water Madeling for the Southern High Plain.s. Texas Tech University Water Resources Center research repurt, Lubbock, TX. January 5, 2001, $298 \mathrm{p}$.

Texas Agricultural Statistical Service. Teras Agricultural Statistics 2000. United States Department of Agriculture and Texas Department of Agriculture, 2000, 156p. 
Appendix. Paraneter Estimates for the Lint Yield, Seed Yield, and Turnout Models; and the Micronaire, Staple Length, and Strength Modcls

\begin{tabular}{|c|c|c|c|c|c|}
\hline \multicolumn{2}{|c|}{ Lint Yield } & \multicolumn{2}{|c|}{ Sced Yield } & \multicolumn{2}{|c|}{ Turnout } \\
\hline INT & 458.7779 & INT & 733.2518 & INT & 21.6349 \\
\hline $\mathrm{HU}$ & -0.2827 & HU & -0.5306 & HU & -0.002421 \\
\hline$R F$ & 28.3380 & $\mathrm{RF}$ & 47.6051 & RF & 1.1817 \\
\hline v2 & -45.1264 & V10 & 144.3402 & V2 & -1.07183 \\
\hline V5 & -33.9054 & VII & 233.3580 & V4 & 0.7608 \\
\hline V8 & -35.5474 & WAT & 28.5180 & V5 & -1.0581 \\
\hline VII & 105.6622 & WAT2 & -4.5029 & V6 & 0.7429 \\
\hline WAT2 & -2.6676 & TPH & -9.3998 & V7 & 0.7866 \\
\hline TPH & -7.6505 & TPH2 & -0.2823 & V10 & -2.4316 \\
\hline TPH2 & -0.16003 & TPH3 & 0.001948 & VII & -0.6817 \\
\hline TPH3 & 0.001067 & TPHWAT & 0.8164 & TPH & -0.1281 \\
\hline 'ГPHWAT & 0.4427 & HUWAT & 0.09695 & TPH2 & 0.002373 \\
\hline HUWAT & 0.06864 & RFWAT & -3.4243 & TPH3 & -0.00001717 \\
\hline RFWAT & -2.4027 & RFTPH & 2.2293 & TPHWAT & -0.007562 \\
\hline HUTPH & 0.001122 & V6TPH & 3.8590 & HUWAT & 0.0003198 \\
\hline RFTPH & 1.4730 & VGWAT & -22.9893 & RFWAT & -0.06871 \\
\hline V2TPH & 0.8735 & VIOWAI & -19.9597 & HUTPH & 0,0001203 \\
\hline VGTPH & 3.2029 & VIIWAT & -21.3931 & RFTPH & -0.004842 \\
\hline V7TPH & -0.5118 & & & V2TPH & 0.03387 \\
\hline V2WA'l & -5.7029 & & & VGTPH & 0.02119 \\
\hline V4WAT & -1.5396 & & & V7TPH & -0.02602 \\
\hline V5WAT & -2.5198 & & & V8TPH & $-0.02 ! 62$ \\
\hline V6WAT & -17.9498 & & & V10TPH & -0.01145 \\
\hline V9WAT & -6.5770 & & & VIITPH & -0.01394 \\
\hline VIOWAT & -5.7234 & & & V2WAT & -0.1019 \\
\hline \multirow[t]{5}{*}{ VIIWAT } & -10.03166 & & & V3WAT & 0.1964 \\
\hline & & & & VGWAT & -0.1925 \\
\hline & & & & V9WAT & -0.1017 \\
\hline & & & & VIOWAT & 0.1839 \\
\hline & & & & VIIWAT & 0.1288 \\
\hline \multicolumn{2}{|c|}{$\mathrm{R}^{2}=68.4 \%$} & \multicolumn{2}{|c|}{$\mathrm{R}^{2}=68.7 \%$} & \multicolumn{2}{|c|}{$R^{2}=41.4 \%$} \\
\hline \multicolumn{2}{|c|}{ Micronaire } & \multicolumn{2}{|c|}{ Staple Length } & \multicolumn{2}{|c|}{ Strength } \\
\hline INT & 5.9495 & INT & 1.01287 & INT & 19.1016 \\
\hline $\mathrm{HU}$ & 0.002375 & HU & $0.000(14719$ & HU & 0.006093 \\
\hline V2 & -0.3508 & V2 & 0.03358 & RF & 0.4129 \\
\hline$V_{4}$ & 0.3744 & V3 & -0.05935 & $\mathrm{~V} 2$ & -0.7711 \\
\hline VS & -0.2120 & V8 & 0.03989 & v3 & -4.0935 \\
\hline V7 & 0.2530 & V10 & 0.06808 & V.5 & -1.9683 \\
\hline V9 & -0.1936 & WAT & 0.02105 & VG & -2.2146 \\
\hline V10 & -0.5621 & WAT2 & 0.0004216 & V7 & -0.8857 \\
\hline V11 & -0.2534 & TPH & -0.0009678 & V9 & -1.5564 \\
\hline WAT2 & -0.05151 & HUWAT & -0.00001249 & V10 & -2.4662 \\
\hline WAT3 & 0.001592 & RFWAT & -0.001726 & VII & -2.23 .44 \\
\hline TPH & -0.02991 & RFTPH & 0.0001628 & WAT & 1.1686 \\
\hline TPHWAT & -0.0005341 & V2TPH & -0.0005609 & WAT2 & -0.1105 \\
\hline HUWAT & 0.0003170 & V2WAT & 0.008310 & WAT3 & 0.004560 \\
\hline HUTPH & 0.00002858 & V3WAT & 0.008484 & TPH12 & 0.0004456 \\
\hline RFTPH & 0.11008320 & V5WAT & 0.006715 & TPHWAT & -0.002613 \\
\hline
\end{tabular}


Appendix. (Continued)

\begin{tabular}{|c|c|c|c|c|c|}
\hline \multicolumn{2}{|c|}{ Micronaire } & \multicolumn{2}{|c|}{ Staple Length } & \multicolumn{2}{|c|}{ Strength } \\
\hline VATPH & -0.006329 & VEWAT & 0.005291 & RFWAT & -0.1129 \\
\hline V7TPH & -0.006318 & V7WAT & 0.003435 & HUTPH & -0.00004532 \\
\hline \multirow[t]{17}{*}{ VGWAT } & -0.02474 & V9WAT & 0.004991 & RFTPH & $0.0105 \mathrm{I}$ \\
\hline & & VIOWAT & 0.007070 & V2TPH & -0.03140 \\
\hline & & VIIWAT & 0.005821 & $\mathrm{~V} 4 \mathrm{TPH}$ & 0.01371 \\
\hline & & & & V8TPH & -0.0216 \\
\hline & & & & V9TPH & $-0.0371 \mathrm{I}$ \\
\hline & & & & VIOTPH & -0.03537 \\
\hline & & & & VIITPH & -0.03 .578 \\
\hline & & & & V2WAT & 0.4399 \\
\hline & & & & V.3WAT & 0.2136 \\
\hline & & & & V5WAT & 0.3361 \\
\hline & & & & V6WAT & 0.3742 \\
\hline & & & & V7WAT & 0.157 .3 \\
\hline & & & & VBWAT & 0.1984 \\
\hline & & & & V9WAT & 0.3657 \\
\hline & & & & V1OWAT & 0.56 .39 \\
\hline & & & & VIIWAT & 0.4196 \\
\hline & $\mathrm{R}^{ \pm}=30.4 \%$ & \multicolumn{2}{|c|}{$R^{2}=37.1 \%$} & \multicolumn{2}{|c|}{$R^{2}=40.6 \%$} \\
\hline
\end{tabular}

Note: All paranteters in the final imolels above are statistically significant at the log level ateording to two-litiled Stutent's 1 tests. except those in boldface type. which are only significint at the $20 \%$ level. 